morada, tive os olhos humidecidos ao dizer os adeus da Congregação dos Professores ao funcionario eximio e ao companheiro de todos os momentos. Desaparecia ele coberto das bençãos de cincoenta gerações, que nele viram o homem que só praticara o bem e vivera longa e felizmente, em paz com a conciencia, firme no posto, que tanto dignificou.

0 homem bom foi sepultado no dia do ano bom!

\title{
HOMENAGEM DA FACULDADE DE DIREITO DE SÃO PAULO AO DR. JULIO MAIA
}

Comemorando a data aniversaria da fundação dos cursos juridicos no Brasil, a Faculdade de Direito de São Paulo, em 11 de agosto de 1920, prestou ao seu secretario, JULIO JOAQUIM GONÇALVES MAIA, homenagem tocante e sugestiva, inaugurando o seu retrato, que numa das paginas desta revista se reproduz.

Deu dela o Jornal do Comercio, edição que então se publicava em São Paulo, esta noticia:

A's 20 horas, no salão nobre da Faculdade de Direito, realizou-se a sessão solẹne em homenagem ao Secretario da Faculdade.

Entre as inumeras familias, colegas, ex-alunos da Academia, representações e academicos notámos: Primeiro Tenente Tenorio DE Brito, representando o Dr. Washington Luis, Presidente do Estado; Dr. Jaime Ferreira, Oficial de Gabinete do Sr. Secretario da Fazenda; Dr. Trto Prates, Oficial de Gabinete do Sr. Secretario da Agricultura; Capitão Marinho Sobrinho, ajưante de ordens do Sr. Secretario do Interior; José Lannes, representando o Sr. Secretario do Interior; $10^{\circ}$ Tenente Joaquim Ribeiro Dutra, representando o general Celestino Bastos, comandante da Região Militar; Francisco Amaral, representando o Sr. Delegado Geral; Dr. Benjamin Reis, Secretario da Faculdade de Medicina, representando essa Faculdade e seu respetivo Diretor Dr. Oridio P. dE Campos; Dr. Rodolpho Santiago, representando a Escola Politécnica; José M. QUIrino e Antonio Rodrigues Neto, representando o Gremio Ginasial 
"16 de Setembro"; a Congregação da Faculdade de Direito era representada pelos lentes Drs. Gama Cerqueira, Reynaldo Porchat, Cardozo de Melo Neto, Frederico Steidel, Souza Carvalho, Estevam de Almeida, Spencer Vampré e Aureliano Gusmão; Dr. Renato Maia, representando o Dr. Pedro Lessa, Ministro do Supremo Tribunal; Dr. José de Almeida Prado, Dr. Campos Vergueiro, Dr. Washington de Oliveira, Juiz Federal; Dr. Joaquim Marra, Dr. Vicente Prado, representantes da imprensa e João Ayres de Camargo por esta folha.

O Dr. Julio MaIa foi introduzido no salão nobre acompanhado pelos lentes da Academia e pela comissão promotora dessa homenagem, tocando a banda da Força Publica o hino academico, que foi ouvido de pé pelos presentes, sendo erguidos muitos vivas ao homenageado.

O DR. Reynaldo Porchat, que presidia á mesa, pronunciou um belo discurso, enaltecendo as qualidades, a abnegação, a bondade do Dr. Julio Maia, dando em seguida a palavra ao Dr. Gama Cerquerra, representante da Congregação, que pronunciou o seguinte discurso:

"Caro colega Dr. Julio MaiA

A primeira pessoa a quem a mocidade academica se dirigiu, para que nesta festa classificada pelo Dr. Porchat como altamente simpática exprimisse o sentimento da Congregação da Faculdade de Direito, foi ao seu ilustre diretor o Dr. Herculano de Freitas. A mocidade, como sempre, andou com muito acerto, mas desta vez, por dous motivos. Primeiro, porque ligava assim mais solenidade a esta homenagem; em segundo lugar, porque incumbia dessa missão a um eximio orador, cuja palavra neste recinto tantas vezes tem deixado a todos como encantados. Uma surpresa, porém, á ultima hora, impediu que o nosso diretor fosse o interprete da Congregação. Assim, á ultima hora, veiu a caber-me esta gentissima icumbencia, que nem por um momento hesitei em aceitar, não me importando mesmo com a diferença entre as duas oratorias. Ao convite da mocidade me obrigava o coração que cedesse imediatamente. Pois, sabei, que entre os nossos colegas, o obscuro orador que ora vos dirige a palavra, foi sempre desde as primeiras relações que teve com a Faculdade, mesmo antes de fazer parte do seu corpo decente, um vosso admirador que sinceramente sabia apreciar as vossas qualidades de carater superior.

Perdeu-se de tal maneira na escolha do orador. Na ultima hora, nem me foi dado alinhar por escrito aquilo que havia de vos dizer. Mas isso não é de todo lamentavel, porque aquilo que perder em elegancia de fórma a oração decerto ganhará em sinceridade. 
Foi uma felicissima idéia a da mocidade deixar para este grande dia, em que se comemora a fundação dos cursos juridicos no Brasil, esta festa que constitue o merecido galardão conferido áquele que tem sido exemplo de inteligencia, de dedicação e probidade no cumprimento do dever, áquele que tem oferecido á mocidade um exemplo digno de ser seguido em toda a linha, na vida.

Poderia resumir tudo o que tenho a dizer, porque as elegantissimas e calorosas palavras do nosso diretor interino Dr. Porchat dizem tudo aquilo que era possivel exprimir. A vossa vida é daquelas que em poucas palavras se póde descrever: inteligencia, probidade, dedicação e bondade, eis em que se resume a vossa existencia toda, não só nesta casa, em que sois tão querido, como na sociedade, que muito vos respeita.

Durante trinta e cinco anos, exercestes função em extremo delicada, no meio da mais variada reunião de caracteres e entretanto vos foi dado conseguir que todos esses temperamentos dessemelhantes se reunissem na unanimidade de apreço, da estima, da amizade e da consideração que todos sempre vos tributaram. Isto, quanto ao que vós tendes feito pela Faculdade, diz que representais nesta grande familia, que é ainda um traço da nossa vida intelectual, nesta familia de aspecto um tanto patriarcal representais o papel de filho mais velho ao qual os pais entregam a vigilancia e o meneio dos negocios da familia. Atalaia, vigilante esmerado das nossas leis internas, tendes sabido sempre conciliar, como observou o Dr. Porchat, á severidade a mais intransigente no reto cumprimento das leis, com a delicadeza no trato, a diplomacia que sabe escolher os meios para alcançar os fins, sem atritos, nem dissabores. Assim é que não tendes da mocidade, com a qual sempre lidastes, senão amigos sinceros.

Foi dela que partiu a idéia desta festa, que foi recebida com simpatia e apoiada com calor por todos os professores. Ela saiu dos moços que têm a espontaneidade para fazer justiça a todos quantos se mostram dignos dela. Satisfaz vêr que um velho servidor, como vós, recebe, quando menos podia prever, quando absolutamente não contava com tal, o premio completo de seus trabalhos, de sua dedicação, de sua vida inteira dada ao cumprimento do dever e á manifestação da bondade. E o recebe de um desses movimentos espontaneos da bondade dos moços, a qual se alia toda a plenitude de coração, de alma, de que falou o Presidente desta reunião.

Aceitai, pois, colega, as palavras apressadas pelas quais eu vim transmitir o sentimento dos professores da Faculdade. Sêde sempre feliz com os vossos, para nossa alegria e felicidade" 
As ultimas palavras do ilustre lente, foram cobertas de prolongadas palmas.

Em seguida, foi dada a palavra ao bacharelando Cirristiano Altenfelde Silva Filho que, da tribuna, leu o seguinte discurso. em nome dos academicos de direito.

“Exmo. Sr. Dr. Reynaldo Porchat - Exmos. Srs. representantes do Governo - Douta Congregação - Exmas. senhoras, meus senhores

\section{Colegas}

Sempre carinhosas as festas desta casa. Assim, as despedidas das turmas, enlevadas em sonhos, armadas para a cruzada de Direito e da Vida. A simbólica festa da chave, comovendo os que se separam da tradição academica, sempre quente, eternamente viva.

De flores e de alegrias se enche hoje o velho convento. E o dia da justiça e do reconhecimento.

A homenagem que os estudantes de direito rendem ao Sr. Dr. Julro Mara, sentiram todos desde logo, é da mais profunda gratidão e da maior sinceridade.

Os seus trinta e cinco anos de trabalhos e de energia, trabalhos em prol da dedicação extraordinaria que jámais se viu são uma existencia toda amor pela Faculdade extremecida e zelo e cuidados pela grandeza do ensino.

O seu nome fúlgido está inteiramente ligado a tudo que é da Academia onde, ele, desde que aqui está, sempre foi recebido pelo respeito e veneração da mocidade sincera.

As agitações acadêmicas, nos tempos memoraveis em que as lutas politicas do país tiveram o seu primeiro cenário nestas velhas Arcadas, já o encontraram no posto de que ainda hoje, carinhosamente, leva o seu aplauso ao nacionalismo nascente.

E ele contou como vitórias suas os triunfos esplêndidos da mocidade: - a Abolição decretada primeiro no interior das Arcadas; a República, acariciada pelas gerações vindas para o estudo do direito e daqui saidas com a alma, votada pelos ideais da Pátria, pelo ressurgimento da terra magnanima.

Tudo acompanhou com amor e com carinho, desde as lutas dos partidos em que por vezes se empenharam os diversos grupos acadêmicos, com chefes, programas, candidatos e campanhas, promessas, empenhos e cabala na prática perfeita da politica, que aqui tambem aprendemos, até as nossas provas acadêmicas, o brilhantismo de uns, o fracasso de outros, ao surgir dos batalhões, a sala de armas ao lado da de aulas, a farda prestigiada pelo livro, tudo continua acompanhando sempre o mesmo amigo da mocidade. 
E a Faculdade de Direito continua sendo a Pátria em miniatura - em toda a sua grandeza. Á mocidade de hoje, que já contempla a realização dos sonhos de outrora, que não tem a Abolição a preparar, o negro a redimir e o regime politico a transformar, foi destinada uma missão que tem os mesmos esplendores das epopéias já vividas.

E' nesta Faculdade ainda que o novo ideal surgiu. Aqui falou Bilac e vale dizer que de novo acordou a alma acadêmica.

E o moço de hoje, sem o sentimentalismo do estudante de outros tempos, nascido em uma época em que o militarismo domina, em que o mais vil materialismo constitue a moral ambiente, o filho desta casa é ainda o mesmo sonhador que foram os do século passado.

Em meio a esse novo mundo da materia, ainda surge a legião sagrada a que fremiu de entusiasmo e de resolução ao primeiro apelo de Bilac, o grande morto eternamente vivo em nossos corações e em nossas inteligências, aquela que primeiro firmou o soleníssimo pacto de devotar-se pelo ressurgimento da Pátria, pela ressurreição civismo, pelo combate ás degradações políticas, ao analfabetismo, ás transações inconfessaveis contra os supremos interesses da comunhão e contra a glória e o nome do Brasil -- como já a definiu um nosso grande mestre.

A alma da mocidade não envelhece nem se transforma. Mudem-se os tempos, modifiquem-se as coisas, agitem-se novos problemas, revolte-se tudo - e a mocidade será sempre altiva, sincera e devotada.

O entusiasmo é ainda dos moços e aqueles que descreem do presente não conhecem as maravilhas de que é capaz o puro sentimento de mocidade.

Não são como vós, Sr. Stcretario, que com os trabalhos nesta escola continuamente vos remoçais ao contato alegre com a inteligência e com o estudo.

E por isso que vos vemos entre os primeiros na Liga Nacionalista, essa realizadora do bem e sonhadora da Pátria nova, prova eloquente do que póde a inteligência e a vontade, a dedicação e o carinho da mocidade. Surgiu a Liga Nacionalista quando na Europa ia em pleno fulgor o clarão sinistro e a nossa terra se preparava para a sua participação de civismo no combate á barbaria.

Hoje é uma força que só se justifica pelo apoio constante e valioso que lhe vota a mocidade das escolas e em grande parte os desta Faculdade. A mesma mocidade que atendeu solícita ao brado de alarma do poeta, altiva saiu a cantar a glória dos nossos maiores, inteligente se curvou com a cartilha para o ignorante, ensinando-lhe a conhecer e amar a Pátria, generosa, socorreu a cidade nos tristes dias da miséria e da morte. 
Reunem-se hoje os moços para o cumprimento de um dever para com quem tão alto elevou e soube cumprir o seu.

Porque sois, Sr. Dr. Julio Maia, um exemplo vivo aos moços, de energia e de vontade.

A vossa ação nesta casa tambem se reflete nas provas de civismo que a vossa pessôa veneranda inspira a todos os que convosco aprendem a lição proveitosa, que é a vossa vida, toda votada ao dever e ao amor desta casa.

Para o seu alto renome entrais com elevada contribuição.

Em 35 anos observastes e cumpristes a lei, denunciastes a fráude, velastes pelo direito, exercestes a função de guia amigo e guardador severo da porta deste templo para que os profanos do direito não o viessem macular.

É por isso que hoje se inaugura nesta Secretaria o retrato do seu mais antigo e leal servidor, para que ateste ao futuro em vossa pessôa o cumprimento do dever e em nossa homenagem o reconhecimento sincero do vosso valor, uma pequena paga de muito que vos deve esta casa.

Os grandes exemplos são legados de valor. O homem zeloso do cumprimento do seu dever, qualquer que seja a esfera em que se agite, deve ser elevado ás individualidades de maior destaque.

A maior parte do dever é feita em segredo, longe dos olhos do mundo, o trabalho com dedicação e nobreza que não fez falar de si.

Tudo vos reconhecemos, Sr. Dr. MaIA, o que em vós mais ainda se eleva pelo exemplo que transmite aos moços que convosco nesta casa trabalham.

A felicidade tranquila que resume vossa vida resulta dos atos de abnegação e sacrificios, de generosidade, dos pequenos deveres cumpridos com fidelidade que formaram o vosso carater na honestidade e no trabalho.

E por conhecer o valor inestimavel do bom exemplo, de constância e trabalho, dedicação e honestidade que a mocidade se reune para a vossa festa e para a festa da Academia, que as duas em uma se transforma.

Escolhendo a data de 11 de Agosto para esta inauguração, muito de propósito o fazemos, procurando fugir ao comum das festas com que se comemora a data da fundação dos cursos jurídicos no Brasil.

Tem esta festa uma significação grande para a Academia, no que muito a mereceis SR. Dr. MaIA.

Recebeis, pois, em vossa modestia este golpe que a nossa sinceridade desfere, de envolta com os nossos sentimentos, dos mais sinceros desejos de vossa felicidade pessoal e de vossa Exma. Familia" 
O discurso do jovem bacharelando tambem foi muito aplaudido, sendo nessa ocasião descoberto retrato a óleo do Dr. Julio Maia, que se achava, entre flores naturais, ao lado da mesa que presidia á sessão, trabalho do exímio pintor Paulo do VAlle JUnior. curso:

Levantou-se então o Dr. Julio Mara, que leu o seguinte dis-

"Minhas senhoras e meus senhores

Sinto-me, deveras, comovidissimo com esta honrosa homenagem que o corpo docente e discente da Faculdade de Direito de S. Paulo vem de prestar-me.

Bem sei que não mereço tão elevada distinção atribuindo-a somente a uma das múltiplas generosidades com que costumam manifestar os corações dos professores e alunos desta casa, pois que nada fiz para tanto.

$\mathrm{Na}$ realidade, ha 35 anos, portanto, pouco mais da metade da minha existencia, que me acho na Secretaria deste estabelecimento, exercendo as funções, já de oficial, já de sub-Secretario e, desde 1903, a de Secretario, e, no exercicio de qualquer desses três cargos, constantemente procurei captar e cultivar, com esmero, a simpatia e amizade dos professores e alunos, aproximar estes áqueles e firmar cada vez mais, a solidariedade entre os próprios alunos, para, por esse modo, estabelecer a indispensavel harmonia, que sempre aqui tem reinado.

Diz-me a conciência que, a esse respeito, alguma coisa consegui; e a prova disso, me parece, está patente nesta solenidade que me sensibilizou profundamente e será para mim inesquecivel.

Foi tambem um dos meus principais esforços, no desempenho destes cargos, cumprir o meu dever, e, se faltas cometi, pois reconheço não ser isento de defeitos, não foi com intenção de satisfazer a quem quer que fosse, mas pura e simplesmente devido á dificuldade de aplicar aos casos, então ocorrentes, as regras de direito na interpretação das leis e das ordens, emanadas dos meus superiores hierárquicos.

Se, igualmente, alguma vez fui exigente, quanto ao preenchimento de certas formalidades, não o fui por maldade, mas nos termos das leis que nos têm regido e em beneficios exclusivo dos próprios estudantes, afim de evitar-lhes futuros dissabores.

Quantas vezes, obrigado pelo rigor da lei, não agi contra os ditames do meu coração, procurando aplicar a equidade, sempre que me foi possivel?

Todos os Srs. sabem que, de 1885, época, em que para aqui entrei, o ensino superior no Brasil passou por várias e sucessivas re- 
formas, algumas das quais, pelas suas profundas inovações, foram de efeitos desastrosos para a mocidade e mesmo para o ensino; e apraz-me salientar que, apesar disso, na execução de cada uma dessas reformas, esta Faculdade, felizmente, não registou incidente algum que a fizesse desmerecer do conceito, de que sempre gozou em todo o país; ao contrário, ela continua a ter intatas as suas gloriosas tradições, que são conservadas com verdadeiro carinho pelos lentes e alunos e mesmo pelos funcionários, que aqui viveram e vivem na mais perfeita harmonia, como que constituindo uma só familia, que tem tido por chefes homens notaveis da estatura dos Conselheiros Drs. André Fleury, Leoncio de Carvalho e Barão de Ramalho, Drs. antonio Carlos, Vieira de Carvalho, Barão de Brazilio Machado, João Monteiro, Vicente Mamede, Dino Bueno, João Mendes Junior, amancio de Carvalho, Pinto Ferraz e Herculano de Freitas, os quais, com as suas luzes, souberam imprimir a este instituto de ensino uma direção modelar e invejavel, que faço votos seja perpétua, pelos seus futuros substitutos. E, lembrando, nesta ocasião, os nomes desses ilustres diretores, a todos eles por intermédio do nosso estimadissimo Dr. Herculano de Freitas, apresento o meu intimo reconhecimento pelos bons conselhos que me deram e pela distinção com que sempre me trataram, quer como particular, quer como funcionário deste estabelecimento.

Aos professores, de saudosa memória, que por aqui passaram, deixando traços impereciveis do seu saber, uns já falecidos e outros ainda vivos, como os Drs. Dino Bueno, Pedro lessa e Joño Mendes Junion, que atualmente ocupam posições salientes no pais, e aos lentes que hoje ilustram as suas cátedras, a todos eles, que, com o brilho do seu talento, honram a Faculdade de Direito de São Paulo, e em cada um dos quais tive e tenho um amigo sincero e dedicado seja-me lícito dirigir os meus afetuosos agradecimentos pelos excelentes exemplos que me deram no estrito cumprimento dos seus deveres e no cultivo do seu aprimorado carater.

Aos alunos, - aos que daqui já sairam, dignamente preparados para a carreira que cada um escolheu, e áqueles que ainda aqui estão, haurindo o nectar da ciência do Direito, a todos, emfim, com quem nesta casa tenho convivido na mais respeitosa intimidade, e que, com os seus esforços, tanto têm contribuido para a manutenção da disciplina nesta Faculdade, auxiliando-me com o seu procedimento irrepreensivel, no desempenho das minhas árduas funçōes, deixo consignada a minha mais profunda gratidão, e os concito a que continuem a trabalhar em prol dos grandes ideais, para o engrandecimento da nossa Pátria e maior glória desta Faculdade, onde deverão deixar gravado em caracteres indeleveis, o exemplo proficuo do muito que aqui fizeram, para ser seguido pelas gerações vindouras. 
Aos oradores, que me precederam, confortando-me o coração com a sua palavra eloquente e carinhosa, um apertado abraço de um amigo, que embora de temperamento retraido, lhes será eternamente agradecido. '

Meus caros e bons amigos: os anos vão caindo-me sobre os ombros e os meus cabelos, aos poucos, embranquecendo; mas, no convívio alegre da mocidade, não sinto a minha alma envelhecer"

Prolongados aplausos cobriram as últimas palavras do distinto homenageado, executando a banda de musica, de novo, o Hino Acadêmico, entre vivas e aclamações dos estudantes.

Dada por terminada a sessão pelo Dr. Reynaldo Porchat, foi o Dr. Julio MAIA abraçado e cumprimentado pelos presentes.

Terminada a sessão solene, no salão nobre, sempre acompanhado pelos lentes e pelos alunos da Academia, o Dr. Julio MAIA se dirigiu para a sala da Secretaria da Faculdade, onde lhe foi feita uma significativa manifestação pelos funcionários da Faculdade de Direito que lhe ofereceram uma grande cesta de flores naturais, falando, em nome dos funcionarios, o Dr. Luiz de Vasconcellos que pronunciou uma bela saudação, oferecendo um album ao estimado Secretário da nossa tradicional Academia.

No quadro que foi oferecido ao Dr. Julio Maia ha um cartão de prata, em que está gravada a seguinte dedicatória: "Ao dedicado Secretario Dr. Julio MaIA, ao completar trinta e cinco anos de serviço, homenagem da Faculdade de Direito. A Comissão: Americo

de Moura, Reynaldo Ribeiro, Soares de Mello, Chiristiano A. Silua Filho, Alcides Sampaio, Sylvio Neubern e Frederico Costa CarVALHO".

\section{JUSTA HOMENAGEM}

Com este titulo, A Cigarra, o mensário paulista, que GELASIO PIMENTA fundara e dirigia e tão grande popularidade alcançara, em sua edição de setembro de 1920 , ano VII, n. 143, estampou interessante crônica sobre a homenagem da Faculdade de Dineito ao seu secretário. Subscrevea um pseudônimo.

Foi esta:

Inaugurou-se a 11 de Agosto, perante a Congregação reunida e 0 corpo discente, o retrato do secretário da Academia. Trinta e cinco 
anos de serviço! Muita gente bôa por menos tempo exerceu este emprego, que é a vida. Não leitor malicioso, não creia verdadeira a idéia que embarcou sorrateira em teu espirito. Graças a Deus, Julio MaIA, para ser merecedor da homenagem, tem outros e muito melhores titulos, do que a involuntária antiguidade. Que o digam todos que o conhecem, que com ele trataram, seja uma vez sómente. Sua bondade, sua paciência, seu saber jurídico, bem mereciam mais larga e brilhante escritura. E o que já não fizeram os rapazes para exasperá-lo... Como o metal que tanto mais polido, melhor brilho adquire, assim é no secretário da Faculdade a paciência, aquela virtude excelsa que João Mendes Junion chamou o maior dos heroismos. Quando se iniciaram os exames vestibulares, Julio MaIA, farto de ensinar aos candidatos a fórmula do requerimento, fez afixar o modelo á porta da secretaria. Não passou meia hora que as palavras exames vestibulares estavam transformadas em exames vestabulares, logo patibulares, para nova transformação sofrerem em prostibulares. E calouro houve, que distraido ou ignorante, copiou letra por letra o papel afixado e corrigido, com grande riso para os veteranos, e não menor indignação do secretário. A bondade do Dr. Julio Mala! Parece que lhe dóe na consciencia ver um estudante prejudicado por descuido ou mesmo por desleixo. "O senhor não viu o edital nos jornais? O senhor não lê os jornais? O prazo das matriculas está esgotado ha cinco dias". - "Mas dr. (o estudante inventa uma desculpa) estive doente, no fundo da cama; estive de viagem num lugar onde não havia correio, nem telégrafo, nem jornal, nada, não havia nada". - "Pois outra vez tenha mais cuidado. Perdeu o ano" - "Mas por favor, Dr. Julio Maia..." - "Não tem favor, nem cousa nenhuma. Perdeu o ano". Desconsolado, o rapaz se despede. Mas ao descer a escada ouve uma voz que o chama: "Psiu. olhe aqui. Desta vez está desculpado. Mas olhe, seja mais atento" E a matricula, ou o pagamento da taxa se faz, fóra do prazo para que o moço não sofra a consequência do descuido.

Insensivelmente penso noutro secretário da Academia, seu primeiro lente, o conselheiro José Maria de Avellar Brotéro. Em muitos pontos deve ter sido a antitese do Dr. Julro Maia. Humor variavel, ora chalaceando á portuguêsa, ora irritando os colegas, o diretor, o ministro, os funcionários, os alunos, todo o mundo. Hoje ele seria ranzinza e neurastênico. Naquele tempo dizia-se: rabıjento e maluco. Embirrou Brótéro com certo bedel da Academia, e tanto o aborreceu que afinal, cheias as medidas, para prevenir algum desatino, um dia a vitima exclamou: "Olhe, sr. conselheiro, que eu tambem sou malucol" Salvou-o a semelhança. Brotéro riu a valer, e deixou em paz o pobre homem. 
Uma pequena glória quero que se reconheça a quem de direito. E preciso que se saiba de quem partiu a iniciativa da homenagem ao Dr. Julro Maia. Nem comparecí, confesso, á sessão do Centro Acadêmico em que foi proposta, - mas lancei-a, é filha minha e não largo a paternidade honrosa. Outrem chame a si a maternidade, sempre mais facil de provar, por evidente. A mim, a paternidade. Feito em colaboração, ninguem assistiu, infelizmente. le geste auguste du semeur - valha-me Victor Hugo.

GIL VICENTE 